\title{
Evaluating petrol engine oil deterioration through oxidation and nitration parameters by low-cost IR sensor
}

\author{
H. M. Shinde ${ }^{1,2} \cdot$ A. K. Bewoor ${ }^{2}$
}

Received: 12 August 2019 / Accepted: 12 June 2020 / Published online: 22 June 2020

(c) The Author(s) 2020

\begin{abstract}
For the proper working of the internal combustion engine, engine oil plays a significant role. The performance of the engine is greatly affected by oil that has degenerated. In order to determine the optimal gap between oil changes, it is crucial to measure the deterioration in the engine oil. Multiple parameters like oxidation, nitration, viscosity and so on are brought into use. One of the methods used to quantify the deterioration in the engine oil is the Fourier Transform Infrared (FTIR) spectroscopy. The main parameters of the engine oil are distinguished by this method by utilizing Infrared (IR) absorption at different bandwidths. The two significant parameters in engine oil deterioration are oxidation and nitration. However, the limitation of the FTIR method is that it is more expensive and since it uses huge machinery, it requires a lot of area. Hence, the use of this method is not possible in the field area due to the need for space. It is this major limitation that is the motivation for proposing an inexpensive, yet handy system, using an IR sensor set up, in this paper. This system is used for measuring the transmittance of engine oil that has degenerated. For this paper, we collected random samples at various times from service stations that were specifically authorized. These samples were used in experiments based on the FTIR spectroscopy and UV spectrophotometer and the results were compared using the IR sensor setup. Investigation of the experimental results showed that monitoring oil transmittance using an IR sensor setup is possible, and a robust relationship between oxidation and nitration and the transmittance of the oil was observed. Moreover, a pattern of deterioration for a specific engine oil (SAE 5W30) which is utilized for passenger cars and light duty vehicles was also established.
\end{abstract}

Keywords Engine oil · Oxidation and nitration · IR sensor · Oil deterioration

\section{Introduction}

In order for an internal combustion engine to maintain high levels of performance and yet stay durable, the engine oil that is used is of great significance. Nevertheless, the degradation of oil greatly accelerates if the engine is operated under severe conditions such as very high temperatures, starting up the engine when it is cold or high pressure [1]. To attain the different functions of the engine oil, the parameters of the deterioration in the engine oil undergo multiple

H. M. Shinde

harish.shinde409@gmail.com

1 Department of Mechanical Engineering, Zeal College of Engineering and Research, S. P. Pune University, Pune, India

2 Department of Mechanical Engineering, MKSSS's Cummins College of Engineering for Women, S. P. Pune University, Pune, India changes. As these parameters of deterioration alter, they have a bearing on the quality of the engine oil. As a result, once these parameters reach a specific value, the oil cannot be used in the engine without affecting the performance and working of the engine. For the purposes of prolonging the period for which the oil can be used, different additives are combined with the oil which in turn make the oil a complex hydrocarbon compound. Even as the oil ages, there are many contaminants such as wear debris, soot, water, glycol which are added to the oil when it is serviced. Given the situation, determining and measuring the level of deterioration in the engine oil becomes very complicated. The two other factors that play a role in this process of deterioration are the driving conditions as well as the engine condition. The manufacturers of the vehicles provide instructions and guidelines as to when to change the engine oil. However, these recommendations assume standard driving conditions. If, however, the distance travelled by the vehicle is less than the kilometre range provided by the manufacturer, and proper 
driving conditions are maintained, chances are that the oil may not deteriorate to the point where it has to be changed. Since India needs to import a large portion of the crude oil that is needed in the manufacture of engine oil, there is a great need to quantify the level of deterioration of the oil before it is replaced during servicing. Besides, keeping track of the deterioration levels also supplies pertinent information about coolant or fuel leakages or extreme wear and tear in the engine which may lead to engine failure thereby reducing the gap between service periods of the vehicle. Multiple methods of measuring the levels of deterioration in the laboratory exist. These methods depend on various parameters like sulfonation, nitration, viscosity, oxidation and hence the total acid as well as total base numbers, the content of glycol and water can be determined. The content of the antioxidants in the oil can also be determined. The use of these methods provides the true levels of deterioration. However, since these methods are destructive in nature, it is far cheaper to change the engine oil, especially in the case of light duty vehicles. Hence, there is a great need to quantify the deterioration of engine oil cheaply, utilizing a testing method that is not ruinous.

Engine oil that is being used can be monitored either offline or it can be monitored online. Engines that are large in size and are stationary, definitely need monitoring in the online condition. For obvious reasons, it is more expensive to do online condition monitoring rather than offline condition monitoring. For engines that are up to $1200 \mathrm{cc}$ and are used in light-duty vehicles or passenger cars or vans, determination of the condition of the oil in the engine can be done by an approximation based on parameters of the vehicle. These parameters can be the length of the travel, the speed of the vehicle, the temperature of the engine and so on. One of the limitations of offline analysis that is done in the laboratory is that a lot more time is required for sampling as well as analysing the results.

Sensors can be used for monitoring some chemical as well as physical parameters of the engine oil which can quantify the level of deterioration. One of the tools that has proven to be very powerful as well as practical for analysis of used oil is IR analysis. IR absorption spectrum can detect the deterioration of multiple oil components. Some of these are nitration, oxidation, etc. IR can also detect various contaminants contained in the oil such as anti-wear components, fuel, soot, sulphate by products, glycol, etc. [2, 3]. One of the most critical parameters that is monitored using FTIR spectroscopy [4-6] in the analysis of used oil is the oxidation index, or the oxidation number. When the temperatures are high and there is oxygen present in the air is when the process of oxidation occurs. It is because of the oxidation that a number of compounds that contain carbonyl like carboxylic acids are formed. The chemical effect of oxidation results in the oil becoming acidic because of the presence of carboxylic acids, which leads to corrosion. A physical change that oxidation causes is that the viscosity of the oil rises depending on the amount of oxygen that is used up as a result of the process $[7,8]$. Based on the type of anti-wear components, sulfonate detergents, material antioxidants, carbonyl compounds, hydroxyl and so on, there is infrared radiation absorption at a characteristic wavelength in all of the covalent chemical bonds in organic molecules [9]. Maleville et al. [8] showed how the process of oxidation is influenced by the aromatic and sulphur content as well as the composition of the oils because of the consumption of oxygen and thin film oxidation tests. Measurements taken of variations in the concentration profiles through the carbonyl $(\mathrm{C}=\mathrm{O})$ absorption region $\left(1820-1650 \mathrm{~cm}^{-1}\right)$, it is found that the by-products mentioned above all have vibrations that are highly characteristic in this region, namely, ketones $\left(1725-1705 \mathrm{~cm}^{-1}\right)$, carboxylic acid $\left(1725-1700 \mathrm{~cm}^{-1}\right)$, and ester (1750-1725 $\mathrm{cm}^{-1}$ ) [10-12]. The following ASTM standards have been developed based on the huge amount of information that can be got from the IR spectrum as well as the reliable results: ASTM E2412, D7412, D7414, D7415, D7418, and D7624. This includes determining of the scope of the oil tests using the FTIR method [13]. Literature survey shows that near wave numbers $860 \mathrm{~cm}^{-1}$ and $970 \mathrm{~cm}^{-1}$ is where absorption is the highest and this was related to the oxidation times and for each of these oxidation times, the absorbance rate was quite different from all of the other times [9]. The wavenumbers mentioned above are closer to the IR spectra and measurements of this can be easily taken with the UV spectroscopy method. This method is referred to as a method of absorption spectroscopy/reflectance spectroscopy. For the region that is closer to the IR range measurement and for light in the visible region, this measurement region is used. In order to portion calculable determination of various analytes, this technique is used. Moreover, FTIR method [14] or IR spectral data [15] can be used to determine the total acid number of used mineral oils. In order to monitor oxidative desulphurization of light cycle oil [16] FTIR spectroscopy can also be used. Antioxidants which are possible to be determined by ultra-microelectrodes [17] affect the oxidation of engine oil.

Besides, current literature has also announced partially quantitative supervision of additive depletion (zinc dialkyldithiophosphates) as well as other additive degradation products in an oil matrix that is complex and that emerges from the formulation of oil, deterioration and contamination that includes wear particles, polymerized degradation products as well as soot [18]. Many other types of sensors like inductive, conductive [19] optical and acoustic sensing, integrated sensors for measuring multiple oil properties $[20,21]$ are used for quantification of engine oil deterioration. For detection of base oil oxidation and for increase in acidity [22], thick film (TF) potentiometric 
sensors which depend on ion-selective electrodes are used. Great potential is shown by optical measurement techniques to monitor the quality of oil, particularly in the IR spectral region. An example of this is the multichannel non-diffractive-infrared (NDIR) absorption or IR spectroscopy [23]. This technique is also utilized in laboratories thereby permitting an improved correlation of online data and the results obtained from the lab. Bley et al. [23] displayed a diminished multi-channel IR sensor system to show the difference between rising oxidation and rising contamination of water for synthetic motor oil [23].

As mentioned in the literature published earlier, the development of an infrared sensor that makes use of attenuated total reflectance (ATR) makes possible the supervision of lubricants online [24]. Rauscher, et al. [25] came up with a sensor that is based on the principle of nondispersive infrared absorption measurement along with a setup of transmission that is made up of two thin-film infrared emitters as well as two, four-channel pyroelectric detectors. There are seven types of optical bandpass filters that are brought into use for monitoring alterations in the absorption of the infrared spectrum of marine gearbox oil as well as wind turbine oil.

It would be interesting to know if a study of an analysis of engine oil deteriorated in the laboratory would still hold true for samples taken from the field. There are reports done earlier by researchers on experimentally tested oil that was degraded in the laboratory in an environment that was controlled $[2,7,9,23,26]$. Studies that have been published in the existing literature show how the existance of a diesel particulate filter (DPF) influences the contents of the contaminants such as $\mathrm{Fe}, \mathrm{Cr}, \mathrm{Ni}, \mathrm{Pb}$ as well as the extent of alterations in the physical and chemical parameters like Total Base Number, Total Acid Number, kinematic viscosity during the service life of the engine oil [27]. The primary purpose of this study was to come up with an inexpensive solution to measure the degradation of engine oil using a comparison of the results of the analysis attained from a couple of devices that enabled a rather quick assessment of the quality of the lubricating oils while they were being used with the help of the FTIR technique as well as the transmittance measurement utilizing the UV spectrophotometer. This was in relation to the inexpensive IR sensor setup where transmittance (T) was the amount of light that was transmitted through a solution. The changes that occurred in the specific physiochemical properties of the engine oils while they were being used actually made up the basis of the assessment. The results and discussion section of the paper puts forth information graphically on the intensification and direction of changes in the said physiochemical attributes like the degree of oxidation, the extent of nitration, the alteration in transmittance.

\section{Experimental details}

The goal of this paper is to discuss the use of the three techniques, namely, FTIR spectroscopy, UV spectrophotometer and IR sensor method in the identification of engine oil degradation in terms of the changes in Oxidation (D7414/ASTM E2412), Nitration (D7624/ASTM E2412), Transmittance (ASTM 1421 99). The research work reported in this paper is on the basis of the FTIR method. This method is utilized to measure the degradation in the engine oil in relation to alterations in oxidation and nitration. The UV spectrophotometer technique is used to discover the transmittance of the used engine oil which changes because of the degradation in the engine oil. Samples of oil were gathered from cars at random intervals post an oil change to try out the viability of the IR sensor setup to measure the transmittance of the used oil. The oil that was used was $5 \mathrm{~W} 30$ engine oil. Authorized service stations in the city of Pune were used to collect the samples. For the purposes of the experimentation, the samples of oil were sorted into various classes based on a servicing number which was assigned according to the use of the vehicle in kilometres or months. Samples of oil were taken from the first three servicing cycles.

According to the schedule set up for servicing, the first samples were taken between 0 and $10,000 \mathrm{~km}$ or 12 months whichever comes first. The second sample is usually taken from 10,000 to $20,000 \mathrm{~km}$ that is to say after a span of $10,000 \mathrm{~km}$ after the very first servicing or 12 months before the servicing, whichever comes first. Samples of the oil for the third time were taken from 20,000 to $30,000 \mathrm{~km}$ that is to say, $10,000 \mathrm{~km}$ after the second servicing or 12 months, whichever comes first. For the purposes of this study, Shell 5W30 (API SM) oil samples are utilized as they are ideal for light commercial vehicles, passenger cars and vans. During the sample collection period as per the availability of vehicles for servicing basis, we got 43 samples for the first serving. Sample range for the first servicing was from 2323 to $12,432 \mathrm{~km}$ i.e. in spite of a specific schedule being provided, some vehicles covered more distance than the recommended distance before servicing or some vehicles were available for servicing because of the duration before next the servicing as per the schedule which was 12 months. Similar to earlier discussion for second servicing 28 samples were available from 2248 to $21,896 \mathrm{~km}$ because either the distance was covered or duration between second and first servicing was more than 12 months. Since some of the vehicles that were tested were not driven as much during the first and the second servicing periods, the kilometre range is lower than the kilometre range of the specific servicing period. Oxidation and Nitration measurements of 
the FTIR spectrometer method, which is a very common method, are compared to measurements taken using the IR sensor setup for change in oil transmittance.

\section{Experimental method}

The most obvious properties that can possibly be used to separate used oils from the new oils are the optical properties of the engine lubricants. Some of these optical attributes include reflection, refractive index, transparency and absorbance. Engine oil that has never been used is able to transfer light through without much resistance. As and when degradation sets in, this transmittance reduces due to the presence of impurities like water, fuel and particulate contamination in the lubricant. There are other factors such as nitration, oxidation and so on which also have an impact on the engine oil deterioration. Any alteration in the transmittance of the engine oil is a sign of changes in the oxidation and nitration of the engine oil.

To begin with, measurements for oxidation and nitration are undertaken using the FTIR spectrometer (make: "Nicolet iS10" FT IR spectrometer). The testing is done at the testing laboratory of Valvoline Cummins Pvt. Ltd., Ambernath, Thane. Figure 1 illustrates the FTIR spectrometer. This is an instrument that is highly sensitive to the working environment and therefore it needs to be operated indoors in a laboratory facility where the temperature can be controlled and the moisture is at a minimum. As the first step in the experiment, nitrogen gas purging is carried out. Next, IR window cleaning is done. This is followed by cell calibration (zinc selenide) with $99.99 \%$ purity heptane for a correct path length of 0.01. Desiccators are used to extract moisture and the instrument is recalibrated in case the results are incorrect. At this point, the instrument is all set for readings.
Nicolet iS10 FT IR spectrometer is manufactured by Thermo Scientific Company with OMNIC and Integra software is used for analysis and interpretation of the obtained results.

For analysis of solid samples, the OMNIC software is recommended whereas for analysis of oil, the Integra software is recommended. The OMNIC software can provide FTIR measurement spectra only for two samples. The Integra software, on the other hand, monitors change in the nitration and oxidation values directly using the data stored in the library as reference. There is provision made in this equipment for a reference library that is made up of samples of standard engine oil. However, for exact results, a sample from the first barrel of fresh engine oil is tested and saved in the library with details such as the grade of the oil, the specification, details of additives and the manufacturer and so on. Moreover, this setup also comes with TQ software for the quantification in terms of percentage of the contamination of the parameters such as diesel fuel, glycol water and so on in the engine oil sample. Once each sample is tested the background is verified using $n$-pentane. Hence the background spectrum has to match the reference. Next, the sample of the deteriorated oil is injected with a syringe in a cell for the purposes of measurement as depicted in Fig. 1. There is a restriction of up to $5 \%$ soot contaminated deteriorated oil sample for the measurements of this instrument. Due to the sensitivity of the instrument, care must be taken to ensure that preparation of samples using any chemical should not be done close to the instrument. There should not be any air bubbles present while the oil is filled into the sample cell. The instrument uses the Integra software to compare the oil sample spectra that are deteriorated with the fresh engine lubricant sample spectra data from the library. Having done this, the instrument provides results about the different degradation parameters. A very clear peak can be seen in the IR spectrum of a mineral oil that is oxidised at a specified wavenumber range. Once the fresh oil spectrum is subtracted from the old oil spectrum in

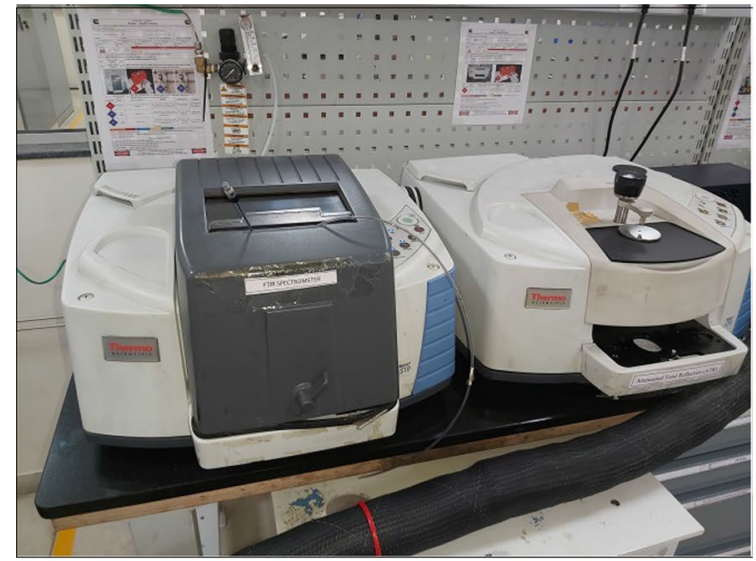

(a) FTIR spectrometer

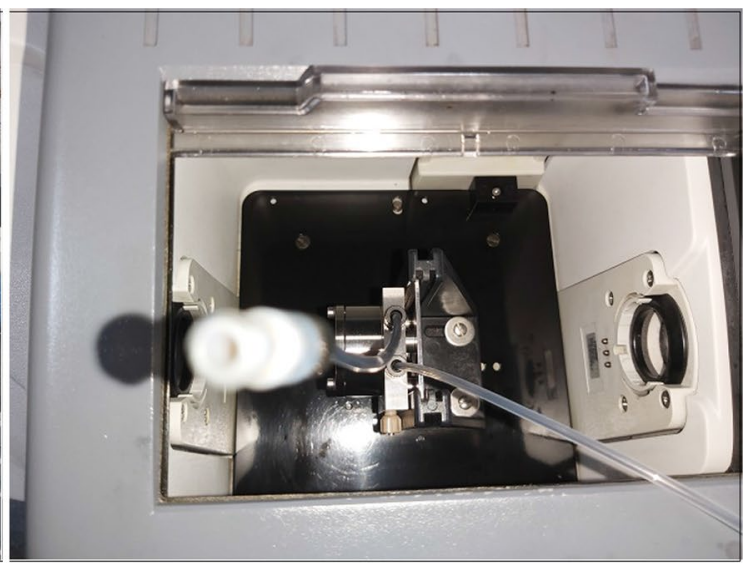

(b) Zinc solenoid cell for engine oil sample

Fig. 1 Nicolet iS10 FT-IR spectrometer 
this region, the oxidation is stated as the IR absorption which is referenced to a thickness absorbance per centimeter (abs/cm) of $1 \mathrm{~cm}$ of the oil layer. This refers to how much of the infrared beam is absorbed in a particular wavelength.

The second alternative technique that is proposed for measuring the deterioration in the oil is the alteration in transmittance. Transmittance $(T)$ refers to the amount of light that is transmitted through a solution. The definition of transmittance is that it is the ratio of the light energy that is transmitted through a sample $(I)$ to the energy that is transmitted through the reference blank. As the compound that is being tested is not there in the reference blank, the transmittance of the reference blank (oil sample) is defined as $100 \% T$.

$T=\frac{I}{I_{0}}$.

This number is multiplied by 100 to determine the percentage transmittance (\%T), the percentage of light transmitted by the substance relative to the reference blank.

$\% T=\frac{I}{I_{0}} \times 100$.
Transmittance measurement is measured through UV Spectrophotometer (make: 'LABINDIA UV 3000') as shown in Fig. 2.

Work mode defines that there are two modes of measurements, i.e. Absorbance mode or transmittance mode. The wavelength range of the instrument is from 190 to $1100 \mathrm{~nm}$. The cuvette is composed of a quartz which is of optical grade. It has two sides that are opaque and two sides that are clear. For the sample, about $11 \mathrm{ml}$ of the oil is taken. Based on literature that has been published earlier [9] the range that is selected is from 850 to $1100 \mathrm{~nm}$ for $10 \mathrm{sam}$ ples. The range for the performance of the trials was from 850 to $1100 \mathrm{~nm}$ and for each repetition, it was increased by $100 \mathrm{~nm}$. After four repetitions of the experiments for 4 wavelengths that is, $850 \mathrm{~nm}, 950 \mathrm{~nm}, 1050 \mathrm{~nm}$ and $1100 \mathrm{~nm}$, we shifted to a wavelength range of 1000-1100 nm. The transmittance value that corresponded to the wavelength was also noted and the trend was plotted against oxidation and nitration. Moreover, transmittance that was measured by a UV spectrophotometer was also noted and its trend was plotted against any change in transmittance that was measured by the IR sensor setup.

Figure 3 illustrates an IR Transmitter which is fixed on an acrylic, transparent, horizontal sheet. This is the third UV/VIS Spectrophotometer
Fig. 2 LABINDIA UV 3000+

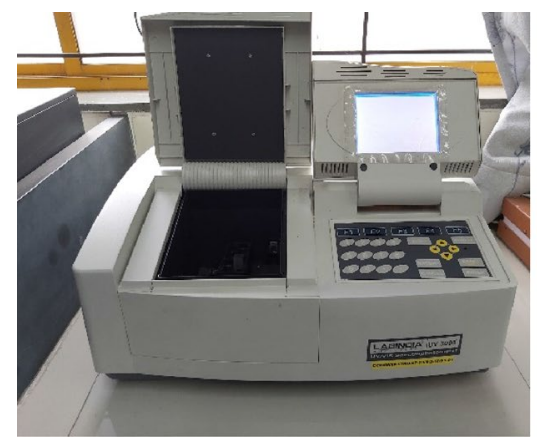

(a) UV Spectrophotometer

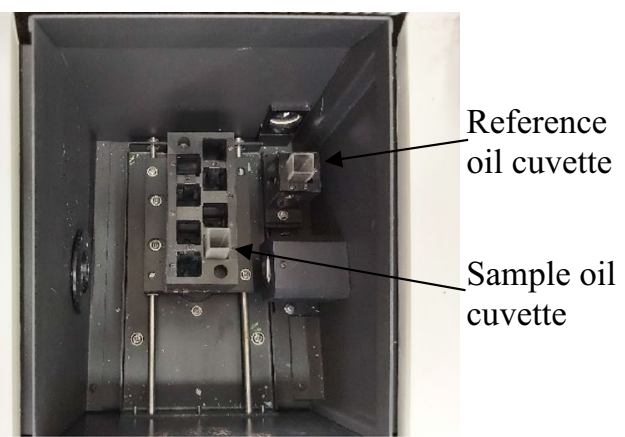

(b) Engine oil sample placement for measurement
Fig. 3 a Schematic representation of change in transmittance measured by IR sensor. b Actual setup photo

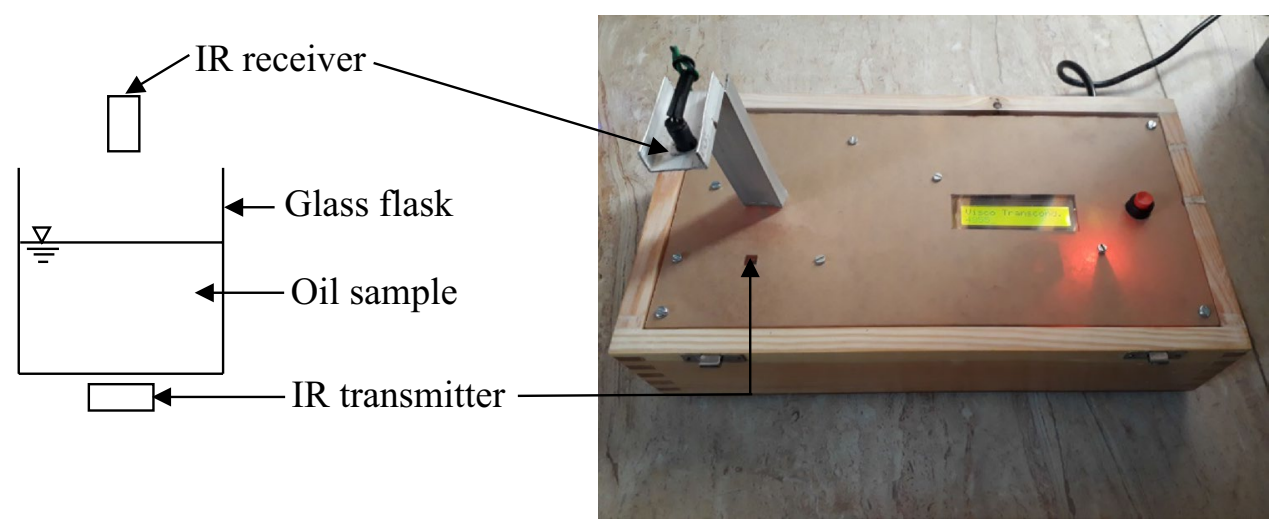

(a) (b) 
proposed IR sensor setup. It is because of this arrangement that most of the other wavelengths that may impact the measurements are not used. The oil sample which is $3 \mathrm{ml}$ under measurement is put in a glass beaker and positioned between the abovementioned transmitter and receiver pair. Its transmittance is affected due to the degradation of the engine oil. Hence, any alteration in the transmittance (mv as output between the IR transmitter and IR receiver pair) will have to be compared with the UV spectrophotometer and the FTIR spectrometer.

Making use of the different devices, the engine oil deterioration reflected in terms of nitration, oxidation, any change in transmittance was measured and the results are discussed in the following section.

\section{Results and discussions}

To begin with, a set of used oil samples which cover a wide range of nitration and oxidation are gathered. Table 1 lists the measurements taken for the samples from the first servicing. It is due to the first servicing, that there are more than 30 samples. Based on the data provided by the manufacturers of engine oils, the permissible limit for both, nitration (abs/cm) and oxidation (abs/cm) is $25(\mathrm{abs} / \mathrm{cm})$. For any value beyond that, the engine oil (5W30) has to be replaced. Based on the literature that has been published so far [1], the oxidation $[\mathrm{abs} /(0.1 \mathrm{~mm})]$ has to be within the range i.e. less than 0.4 . Table 2 lists the measurements taken for the samples from the second servicing. Tables 1 and 2 show the bold values for measured parameters which are beyond permissible limit.

Figure 4 shows FT-IR absorbance spectra of the engine oils. All these graphs are taken from OMNIC software module which was provided with FTIR setup. Figure 4a shows spectra of fresh engine oil with an overlap of 10E sample used engine oil with a nitration value of $9(\mathrm{abs} / \mathrm{cm})$ and an oxidation value of $11(\mathrm{abs} / \mathrm{cm})$. Figure $4 \mathrm{~b}$ shows spectra of fresh engine oil with an overlap of $14 \mathrm{G}$ sample used engine oil as it was observed that the pick for nitration and oxidation was lower than the 10E sample ID engine oil. Therefore the nitration value for the sample was $8(\mathrm{abs} / \mathrm{cm})$ and the oxidation value was $5(\mathrm{abs} / \mathrm{cm})$. Figure $4 \mathrm{c}$ shows higher picks with respect to fresh engine oil with an overlap of $18 \mathrm{D}$ sample used engine oil which showed a nitration value of 29 (abs/ $\mathrm{cm})$ and an oxidation value of $15(\mathrm{abs} / \mathrm{cm})$. Figure $4 \mathrm{~d}$ shows a maximum pick, hence with respect to fresh engine oil with an overlap of 180 sample used engine oil the nitration value was also higher $49(\mathrm{abs} / \mathrm{cm})$ and the oxidation value was $28(\mathrm{abs} / \mathrm{cm})$. As per a discussion in the FTIR spectrometer measurement procedure the results were automatically compared with respect to fresh engine oil reference and by using Integra software results were directly provided for nitration as well as oxidation. No manual calculations or pick point was required for this model of FTIR spectrometer. This spectra analysis graph is used as a reference to observe the difference in picks at the particular region for nitration and oxidation parameter measurement on FTIR spectrometer (see Table 2).

Figure 5 depicts a comparison of the range of nitration attained by making use of the FTIR spectroscopy technique and the output obtained using the IR sensor setup transmittance. Regression analysis done on the data shows a linear trend with $R^{2}=0.88$ and absolute average relative deviation (AARD) $\%$ for linear curve fitting is 2.34 which is shown in Fig. 5. For oil that was unused, the output from the IR sensor setup is $4972 \mathrm{mv}$ with a gradual decrease to $318 \mathrm{mv}$ since the nitration rises in used oil. It can be seen that at the beginning, due to a rise in the nitration value, there is no change in the results of the IR sensor setup. A total of thirteen samples can be seen to have a nitration value that is higher than 25 (abs/cm) above the acceptable limit. 20\% of the samples have a nitration value that is less than $10(\mathrm{abs} / \mathrm{cm}) .19 \%$ of the samples have a nitration value in the range of 10-20 (abs/ $\mathrm{cm})$. However, $45 \%$ of the samples are on the verge of the replaceable limit of deterioration with values in the range of 20-25 (abs/cm). Figure 6 illustrates the values for oxidation of the used engine oils attained with the FTIR spectrum and the results of transmittance as measured by the IR sensor setup. Figure 6 also depicts a correlation that is reasonable between the results attained from the samples collected randomly from the range of samples collected from the first servicing. A regression analysis done shows a correlation of $R^{2}=0.80$ and absolute average relative deviation (AARD) $\%$ for linear curve fitting is 2.94 between the transmittance and the oxidation. Moreover, the measuring and evaluation done by the IR transmitter sensor is on a particular band rather than a single wavelength the sensitivity range is from 800 to $1100 \mathrm{~nm}$ and the peak response is at $920 \mathrm{~nm}$. Figure 7 below shows the results of the variation of nitration for the used oil samples from the second servicing using the IR sensor setup. In Fig. 7 the regression analysis shows a polynomial trend with $R^{2}=0.88$ and absolute average relative deviation (AARD) \% for curve fitting is 2.12. For the unused oil samples, the IR sensor setup output is $4972 \mathrm{mv}$ with a gradual decrease to $318 \mathrm{mv}$ since there is a rise in the nitration of the used oil. The samples of the degraded engine oil have a value of $9\{$ Nitration $(\mathrm{abs} / \mathrm{cm})\}$ till the maximum value of the deteriorated oil sample is 49. A comparison of the samples of oil taken from the first servicing and the second servicing shows a change in the nitration trend which is uniform with respect to the IR sensor setup. A total of 8 samples have a nitration value that is higher than $25(\mathrm{abs} / \mathrm{cm})$ above the acceptable limits. This is out of the 28 samples collected from the second servicing.

Figure 8 reflects the values of the oxidation of the used engine oils that were obtained with the FTIR spectrum 
Table 1 First servicing oil samples testing data

\begin{tabular}{|c|c|c|c|c|c|c|}
\hline Sample ID & Engine $(\mathrm{km})$ & $\begin{array}{l}\text { Previous } \\
(\mathrm{km})\end{array}$ & Oil (km) & $\begin{array}{l}\text { Nitration, } \\
(\text { abs } / \mathrm{cm})\end{array}$ & $\begin{array}{l}\text { Oxidation, } \\
(\mathrm{abs} / \mathrm{cm})\end{array}$ & $\begin{array}{l}\text { Transmittance } \\
\text { (IR sensor) }\end{array}$ \\
\hline New Oil & 0 & 0 & 0 & 0 & 0 & 4972 \\
\hline 01B & 12,432 & 0 & 12,432 & 23 & 12 & 3282 \\
\hline $02 \mathrm{~A}$ & 4620 & 0 & 4620 & 8 & 7 & 4265 \\
\hline 02B & 5250 & 0 & 5250 & 42 & 23 & 318 \\
\hline $02 \mathrm{E}$ & 10,142 & 0 & 10,142 & 11 & 9 & 4894 \\
\hline 03B & 9131 & 0 & 9131 & 32 & 20 & 1834 \\
\hline $03 \mathrm{C}$ & 11,955 & 0 & 11,955 & 29 & 18 & 1228 \\
\hline 08C & 9800 & 0 & 9800 & 21 & 13 & 3588 \\
\hline $08 \mathrm{D}$ & 10,000 & 0 & 10,000 & 38 & 22 & 754 \\
\hline $10 \mathrm{~A}$ & 4609 & 0 & 4609 & 15 & 13 & 4283 \\
\hline $10 \mathrm{~B}$ & 7000 & 0 & 7000 & 21 & 14 & 3412 \\
\hline $10 \mathrm{E}$ & 10,000 & 0 & 10,000 & 9 & 11 & 4894 \\
\hline $10 \mathrm{~F}$ & 10,000 & 0 & 10,000 & 23 & 19 & 1709 \\
\hline $11 \mathrm{E}$ & 9012 & 0 & 9012 & 24 & 19 & 962 \\
\hline $11 \mathrm{H}$ & 1040 & 0 & 1040 & 6 & 7 & 4953 \\
\hline $11 \mathrm{I}$ & 11,004 & 0 & 11,004 & 15 & 10 & 3445 \\
\hline $12 \mathrm{C}$ & 8655 & 0 & 8655 & 27 & 15 & 1839 \\
\hline $12 \mathrm{E}$ & 9433 & 0 & 9433 & 38 & 31 & 227 \\
\hline $12 \mathrm{I}$ & 10,200 & 0 & 10,200 & 23 & 15 & 2970 \\
\hline $12 \mathrm{~J}$ & 10,285 & 0 & 10,285 & 36 & 21 & 1228 \\
\hline $12 \mathrm{~K}$ & 10,337 & 0 & 10,337 & 41 & 25 & 559 \\
\hline $12 \mathrm{~L}$ & 10,500 & 0 & 10,500 & 17 & 11 & 2489 \\
\hline $12 \mathrm{M}$ & 10,900 & 0 & 10,900 & 24 & 15 & 3100 \\
\hline $12 \mathrm{~N}$ & 11,700 & 0 & 11,700 & 33 & 20 & 897 \\
\hline $12 \mathrm{O}$ & 11,800 & 0 & 11,800 & 8 & 9 & 4907 \\
\hline $14 \mathrm{D}$ & 7678 & 0 & 7678 & 17 & 11 & 3848 \\
\hline $14 \mathrm{G}$ & 9485 & 0 & 9485 & 8 & 5 & 4296 \\
\hline $14 \mathrm{I}$ & 11,000 & 0 & 11,000 & 34 & 19 & 1092 \\
\hline $14 \mathrm{~J}$ & 12,000 & 0 & 12,000 & 18 & 12 & 2346 \\
\hline $17 \mathrm{~A}$ & 10,424 & 0 & 10,424 & 25 & 21 & 2782 \\
\hline $17 \mathrm{~B}$ & 3328 & 0 & 3328 & 6 & 6 & 4953 \\
\hline $17 \mathrm{C}$ & 6801 & 0 & 6801 & 21 & 16 & 2600 \\
\hline $17 \mathrm{I}$ & 9577 & 0 & 9577 & 21 & 15 & 3100 \\
\hline $17 \mathrm{~K}$ & 2323 & 0 & 2323 & 5 & 8 & 4953 \\
\hline $18 \mathrm{G}$ & 7673 & 0 & 7673 & 21 & 19 & 2632 \\
\hline $19 \mathrm{~A}$ & 12,046 & 0 & 12,046 & 35 & 22 & 604 \\
\hline $19 \mathrm{C}$ & 7053 & 0 & 7053 & 22 & 14 & 1508 \\
\hline $19 \mathrm{~J}$ & 11,123 & 0 & 11,123 & 8 & 6 & 4953 \\
\hline $19 \mathrm{~L}$ & 4724 & 0 & 4724 & 19 & 15 & 2970 \\
\hline $20 \mathrm{D}$ & 5193 & 0 & 5193 & 11 & 7 & 4907 \\
\hline $20 \mathrm{G}$ & 9182 & 0 & 9182 & 31 & 19 & 1534 \\
\hline $20 \mathrm{I}$ & 8968 & 0 & 8968 & 30 & 22 & 1995 \\
\hline $20 \mathrm{R}$ & 2949 & 0 & 2949 & 6 & 3 & 4914 \\
\hline
\end{tabular}

compared to the transmittance values measured by the IR sensor setup output. The figure also depicts a reasonable correlation to the output from the samples selected randomly from the range of the second servicing. A correlation of $R^{2}=0.85$ and absolute average relative deviation
(AARD) \% for quadratic curve fitting is 3.46 was noted between the transmittance and oxidation when regression analysis was conducted. Moreover, out of a total of 28 samples of degraded oil, 2 of the samples have an oxidation value that is more than 25 (abs/cm) over and above the 


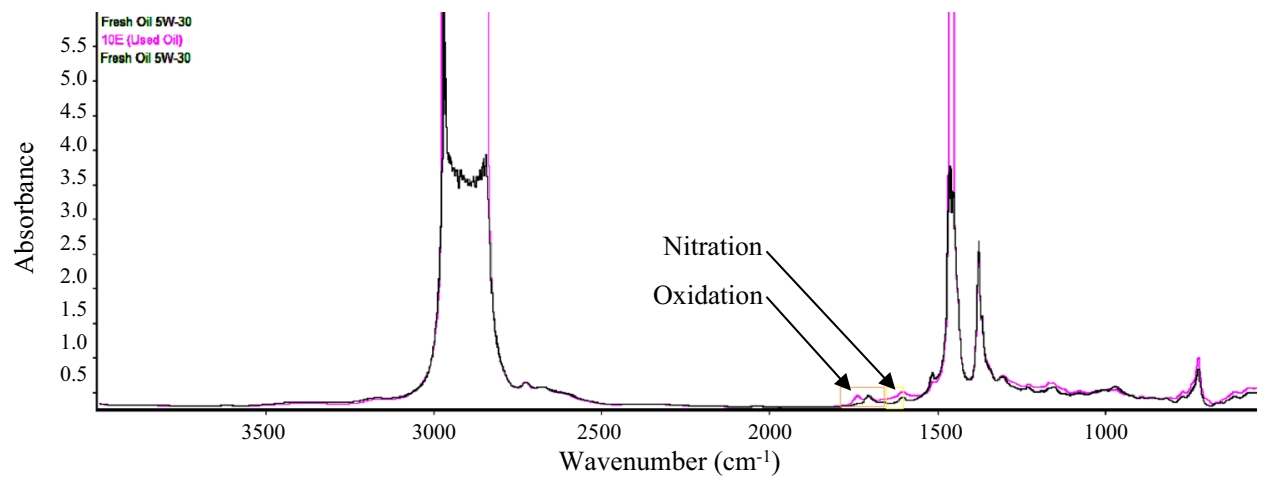

(a) 10E sample ID used engine oil FTIR spectra.

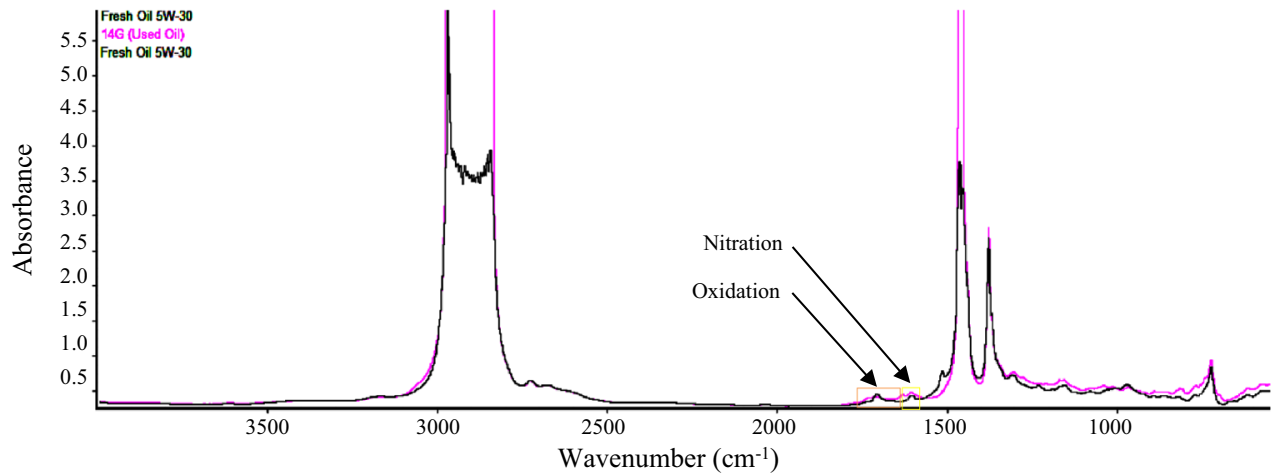

(b) 14G sample ID used engine oil FTIR spectra

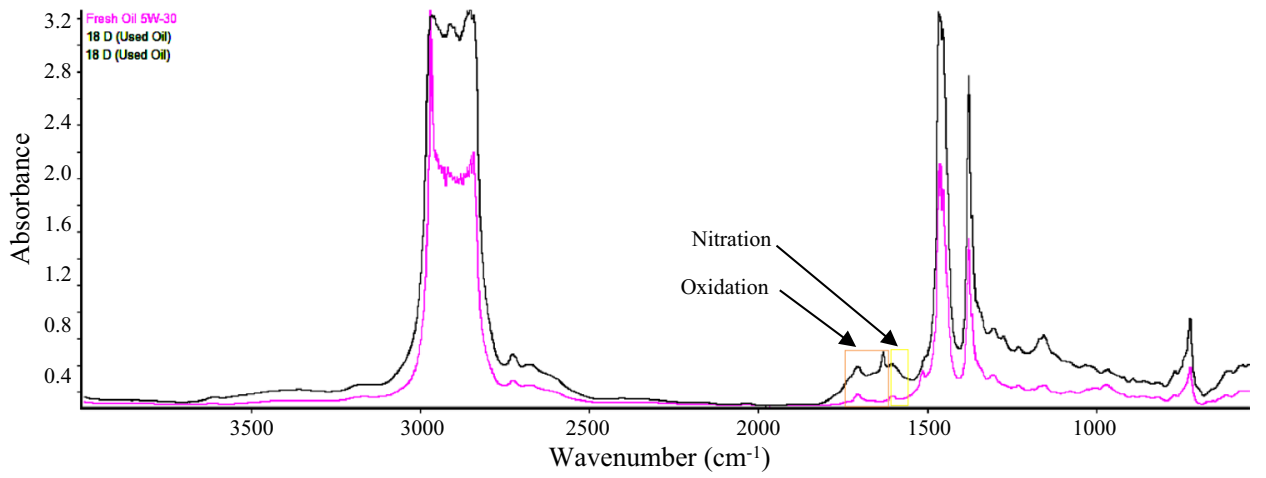

(c) 18D sample ID used engine oil FTIR spectra

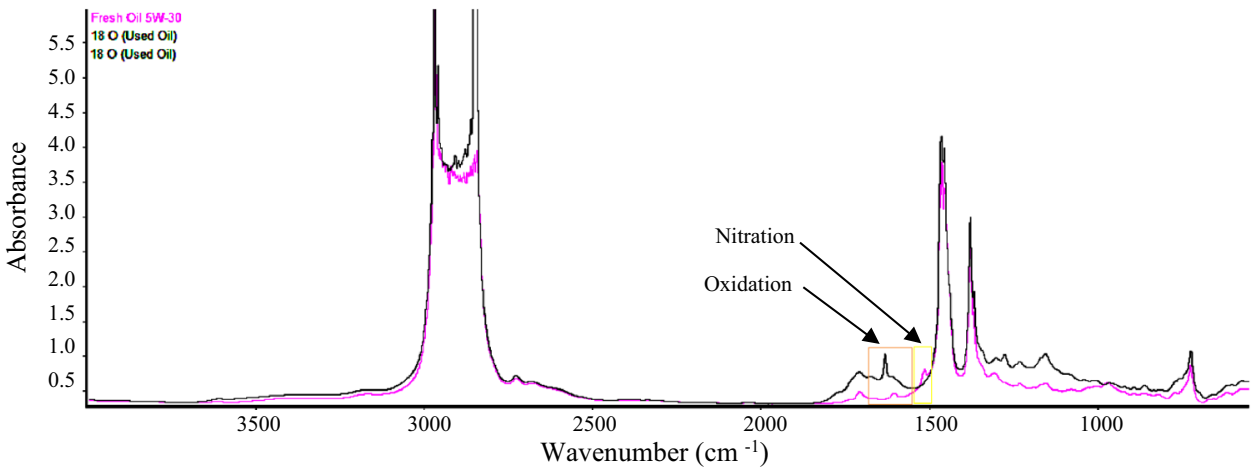

(d) 180 sample ID used engine oil FTIR spectra

Fig. 4 OMNIC software spectra analysis of a 10E, b 14G, c 18D, d 180 sample ID used engine oil sample compared w.r.to fresh engine oil sample 
Table 2 Second servicing oil samples

\begin{tabular}{|c|c|c|c|c|c|c|}
\hline Sample ID & Engine km & Previous km & Oil km & $\begin{array}{l}\text { Nitration } \\
(\text { abs/cm) }\end{array}$ & $\begin{array}{l}\text { Oxidation } \\
\text { (abs/cm) }\end{array}$ & $\begin{array}{l}\text { Transmittance } \\
\text { (IR sensor) }\end{array}$ \\
\hline $17 \mathrm{E}$ & 19,727 & 8032 & 11,695 & 27 & 15 & 3003 \\
\hline $17 \mathrm{G}$ & 19,522 & 12,966 & 6556 & 24 & 13 & 4030 \\
\hline $17 \mathrm{~J}$ & 14,751 & 8927 & 5824 & 47 & 38 & 468 \\
\hline $17 \mathrm{~L}$ & 17,366 & 10,347 & 7019 & 18 & 11 & 3802 \\
\hline 170 & 14,387 & 7735 & 6652 & 14 & 9 & 4452 \\
\hline $17 \mathrm{~T}$ & 20,433 & 9183 & 11,250 & 25 & 14 & 2649 \\
\hline $17 \mathrm{U}$ & 7031 & 3151 & 3880 & 23 & 14 & 3055 \\
\hline $18 \mathrm{~A}$ & 21,896 & 18,339 & 3557 & 12 & 7 & 4953 \\
\hline $18 \mathrm{C}$ & 8648 & 2039 & 6609 & 25 & 15 & 2132 \\
\hline $18 \mathrm{D}$ & 18,992 & 9567 & 9425 & 29 & 15 & 2142 \\
\hline $18 \mathrm{~K}$ & 6771 & 6593 & 178 & 34 & 17 & 1874 \\
\hline $18 \mathrm{~L}$ & 3453 & 1673 & 1780 & 15 & 10 & 3912 \\
\hline $18 \mathrm{M}$ & 2594 & 596 & 1998 & 9 & 8 & 4953 \\
\hline $18 \mathrm{~N}$ & 18,465 & 4559 & 13,906 & 32 & 20 & 1849 \\
\hline $18 \mathrm{O}$ & 2248 & 682 & 1566 & 49 & 28 & 370 \\
\hline 19B & 15,000 & 10,022 & 4978 & 17 & 10 & 3619 \\
\hline 19D & 10,113 & 6164 & 3949 & 16 & 10 & 4426 \\
\hline $19 \mathrm{M}$ & 17,381 & 9259 & 8122 & 14 & 9 & 4658 \\
\hline $19 \mathrm{~N}$ & 19,530 & 8560 & 10,970 & 9 & 10 & 4953 \\
\hline $20 \mathrm{C}$ & 13,941 & 6542 & 7399 & 14 & 14 & 3126 \\
\hline $20 \mathrm{~L}$ & 17,327 & 8327 & 9000 & 15 & 13 & 4030 \\
\hline $20 \mathrm{M}$ & 18,563 & 9563 & 9000 & 9 & 3 & 4953 \\
\hline 20Q & 21,248 & 11,223 & 10,025 & 21 & 13 & 1930 \\
\hline $20 \mathrm{~S}$ & 17,210 & 9850 & 7360 & 30 & 18 & 1794 \\
\hline $20 \mathrm{~T}$ & 17,296 & 9851 & 7445 & 9 & 6 & 4842 \\
\hline $20 \mathrm{~V}$ & 19,896 & 11,982 & 7914 & 26 & 14 & 2873 \\
\hline $21 \mathrm{~N}$ & 16,581 & 9850 & 6731 & 25 & 17 & 2340 \\
\hline 22Q & 16,788 & 9175 & 7613 & 25 & 18 & 2444 \\
\hline
\end{tabular}

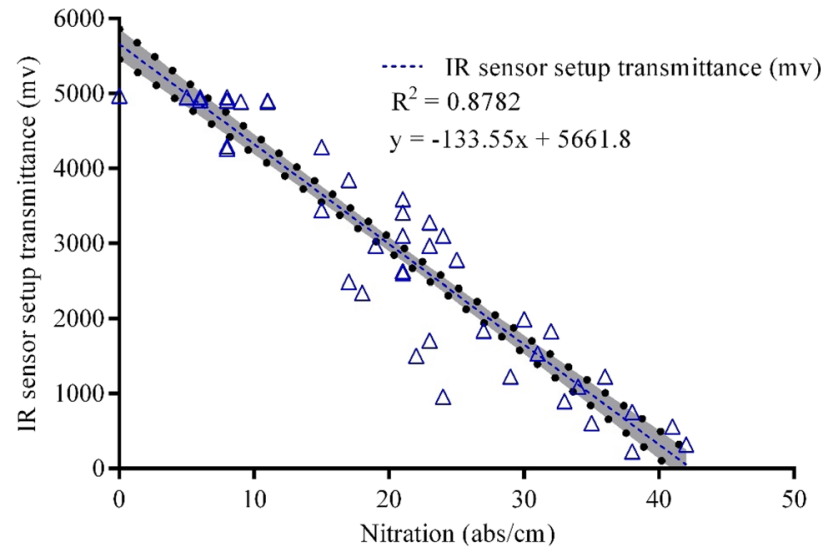

Fig. 5 Nitration $(\mathrm{abs} / \mathrm{cm})$ versus change in Transmittance measured by IR sensor setup for first servicing deteriorated oil samples

acceptable limit. To define a good fit between the transmittance and nitration or oxidation both RMSE calculations and regression analysis was taken into consideration.

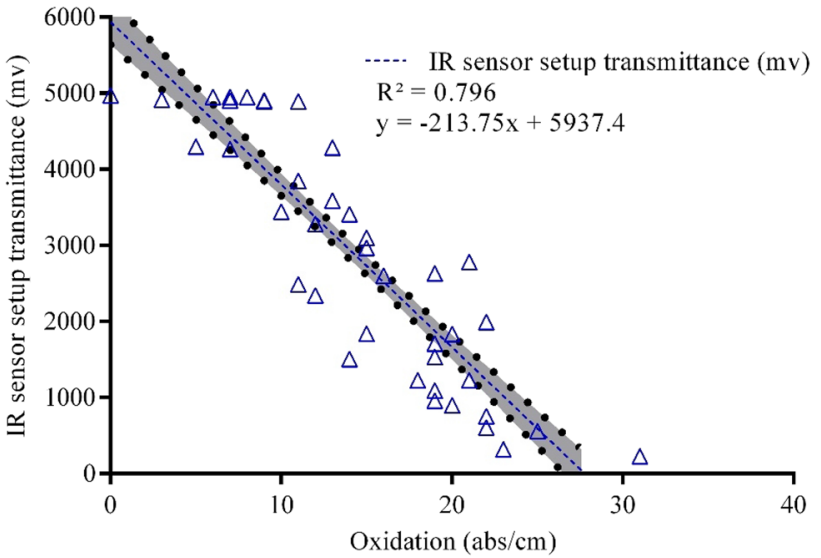

Fig. 6 Oxidation (abs/cm) versus change in Transmittance measured by IR sensor for first servicing deteriorated oil samples

Curve fittings shown in Figs. 5, 6, 7 and 8 are with 95\% confidence interval and $P$ value for all these models 


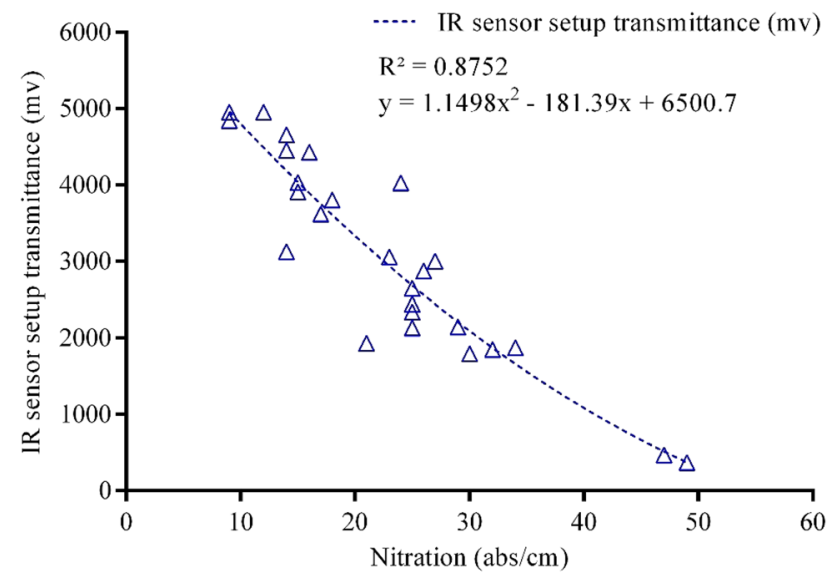

Fig. 7 Nitration (abs/cm) versus change in Transmittance measured by IR sensor setup for second servicing deteriorated oil samples

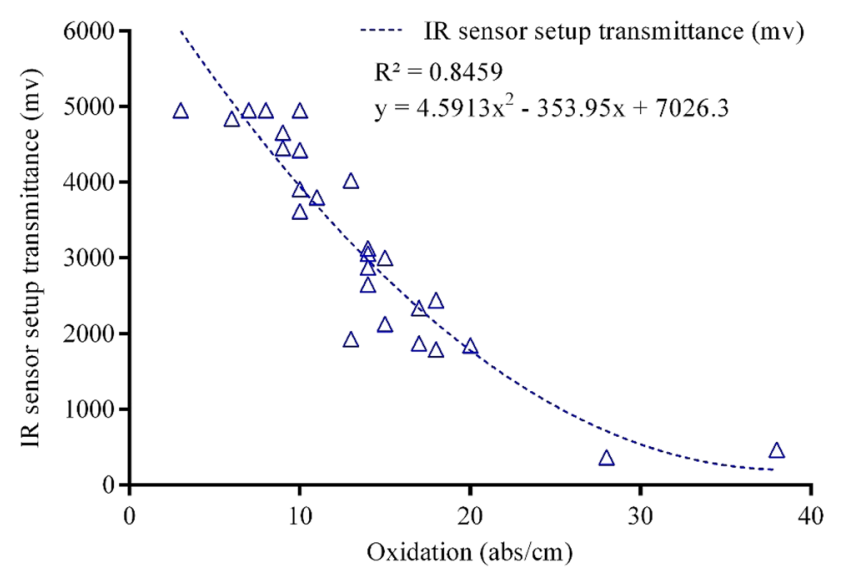

Fig. 8 Oxidation (abs/cm) versus change in Transmittance measured by IR sensor for second servicing deteriorated oil samples

are $<0.05$. It can also be noted that the root mean square error (RMSE) calculations of the oil samples from the first servicing are higher compared to similar values for the second servicing samples. Since the RMSE calculations were used with the second servicing oil samples was a selection parameter for curve fitting, a quadratic equation was chosen over a linear equation for curve fitting. In addition, the second servicing oil samples curve is more appropriate with respect to the oxidation and nitration parameters of the engine oil degradation. Because the number of parts that experience friction in case of the second serving oil condition will be much lower as compared to the first servicing oil samples. Therefore, change in transmittance measurably effected by oxidation or nitration and not by wear particle contamination as compared to first servicing oil samples. Data that has been published by prior researchers, $[2,13,18]$ shows that there is an increase in the values of oxidation and nitration. According to literature published earlier, the maximum value of oxidation for gasoline (petrol) vehicles is about 36 (abs/ $\mathrm{cm})$ and the value for the nitration is about $33(\mathrm{abs} / \mathrm{cm})$ after the vehicle has been driven for $15,500 \mathrm{~km}$ for a $5 \mathrm{~W} 30$ grade engine oil [13]. A different study [18] that studied oil deterioration measurement noted that as the number of kilometres driven goes up, the nitration and oxidation values go up uniformly. Both of these measurements are performed for the same vehicle/vehicles from which samples of oil are collected at a fixed interval. Then again, as per literature that has been published in the past, it can be observed that once the additives such as antioxidants, base reserve and ZDDP are depleted, after the vehicle has been driven for $7000 \mathrm{kms}$, a drastic change takes place in both, the oxidation as well as the nitration parameters of the degraded engine oil sample.

As Fig. 9 shows, good correlation $R^{2}=0.91$ (absolute average relative deviation (AARD) \% for curve fitting is little poor because transmittance values less then $900 \mathrm{mv}$ by setup are poorly correlated to transmittance $\%$ measured by UV spectrophotometer) is noted between the IR sensor measured transmittance and the transmittance measured by the UV spectrophotometer which happens to be a standard lab equipment. Hence the transmittance measured by the IR sensor setup is very comparable in terms of the transmittance. One more notable fact is that for a larger number of samples, the deterioration in the nitration was more compared to the oxidation. Therefore, it can be seen from the experiments that are performed that the work done provides an inexpensive and straightforward alternative to measure the degradation in the engine oil outside in the field.

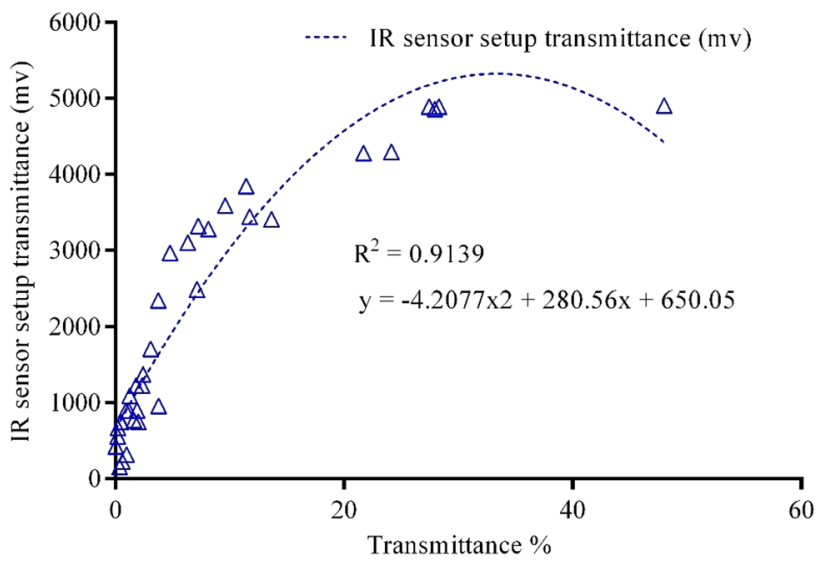

Fig. 9 IR sensor measured transmittance versus Transmittance measured by UV spectrophotometer for first servicing deteriorated oil samples 
Research done into the cost factors of the equipment shows that the cost of FTIR is about Rs. 27,00,000/(depending on the make and the model) and the cost of a UV spectrophotometer is about Rs. 2,80,000/-. Again, prices may vary based on the make and model [28]. The manufacturing cost of the proposed IR sensor set up is about Rs. 4400/-. Therefore, it can be seen that the cost of this setup is drastically lower than the standard methods that are used to measure the degradation in the engine oil.

\section{Conclusions}

As per the objectives laid out in this research work, analysis is carried out for samples of Shell 5W30 oil. A discussion of the results of the analysis is done and presented with a primary focus on the values for nitration, oxidation and transmittance. Moreover, the results of this research provide data about the degradation levels of randomly collected oil samples in the field. This research has been successful in implementing a setup for taking such measurements which are extremely practical and can be done outdoors on the field. The following conclusions have been drawn based on the research:

- The experimentation clearly demonstrates the capability of the IR sensor setup as a low-cost detector and transmitter. It captures significant information that can be used for analysis with requisite sensitivity.

- The proposed setup provides an inexpensive solution and shows great potential for offline monitoring of engine lubricants.

- Compared to oxidation correlation provided by this handy set up namely, $\left(R^{2}=0.84\right)$, the nitration correlation that it provides is better, namely $\left(R^{2}=0.87\right)$. Therefore, it can be concluded that it is more appropriate for nitration measurement and will be able to measure degradation in engine oil in the field.

- It has the capability to measure transmittance with reasonable accuracy $\left(R^{2}=0.91\right)$ because the range of this proposed set up is closer to the measuring range of the UV spectrometer near the IR range.

- Further research can be based on the work done in this paper to develop an inexpensive technique for analysis and quantification of the quality of engine oil.

- Other spectroscopic parameters such as water, glycol content and some conditions such as soot which are relevant to the monitoring of engine oil may also be measured by this set up with a selection of appropriate wavelength transmitter and receiver pair.

- Different driving conditions of specific vehicles may be the cause for slightly scattered points.
Acknowledgements This work was funded by Rajiv Gandhi Science and Technology Commission (RGSTC) under its scheme 'Assistance for Science and Technology Applications', Project Id: RGSTC/File2017/DPP-177/CR-33. The authors are grateful to Valvoline Cummins Private Ltd., Ambernath, Thane for supporting this work.

\section{Compliance with ethical standards}

Conflict of interest The authors declare that there is no conflict of interests regarding the publication of this paper.

Open Access This article is licensed under a Creative Commons Attribution 4.0 International License, which permits use, sharing, adaptation, distribution and reproduction in any medium or format, as long as you give appropriate credit to the original author(s) and the source, provide a link to the Creative Commons licence, and indicate if changes were made. The images or other third party material in this article are included in the article's Creative Commons licence, unless indicated otherwise in a credit line to the material. If material is not included in the article's Creative Commons licence and your intended use is not permitted by statutory regulation or exceeds the permitted use, you will need to obtain permission directly from the copyright holder. To view a copy of this licence, visit http://creativecommons.org/licenses/by/4.0/.

\section{References}

1. Gołębiowski W, Wolak A, Zając G (2018) Definition of oil change intervals based on the analysis of selected physicochemical properties of used engine oils. Combust Engines 172(1):1-7

2. Agoston A, Schneidhofer C, Dörr N, Jakoby B (2008) A concept of an infrared sensor system for oil condition monitoring. Elektrotech Inf 125(3):71-75

3. Kral JJ, Konecny B, Kral J, Madac K, Fedorko G, Molnar V (2014) Degradation and chemical change of longlife oils following intensive use in automobile engines. Meas J Int Meas Conf 50(1):34-42

4. van de Voort FR, Sedman J, Cocciardi RA, Pinchuk D (2006) FTIR condition monitoring of in-service lubricants: ongoing developments and future perspectives. Tribol Trans 49(3):410-418

5. Coates JP, Setti LC (1986) Infrared spectroscopic methods for the study of lubricant oxidation products. ASLE Trans. 29(3):394-401

6. Owrang F, Mattsson H, Olsson J, Pedersen J (2004) Investigation of oxidation of a mineral and a synthetic engine oil. Thermochim Acta 413(1-2):241-248

7. Faure D, Hipeaux JC, Guevellou Y, Legros A (2006) Oxidation stability of gasoline engine lubricants: effect of base-oil chemistry in laboratory and engine tests. Tribotest 5(4):337-360

8. Maleville X, Faure D, Legros A, Hipeaux JC (2006) Oxidation of mineral base oils of petroleum origin: the relationship between chemical composition, thickening, and composition of degradation products. Lubr Sci 9(1):1-60

9. Abdul-Munaim A, Holland T, Sivakumar P, Watson D (2019) Absorption wavebands for discriminating oxidation time of engine oil as detected by FT-IR spectroscopy. Lubricants 7(3):24

10. Macián V, Tormos B, Gómez YA, Salavert JM (2012) Proposal of an FTIR methodology to monitor oxidation level in used engine oils: effects of thermal degradation and fuel dilution. Tribol Trans 55(6):872-882

11. Powell J, Compton D (1993) Automated FT-IR spectrometry for monitoring hydrocarbon-based engine oils. Lubr Eng 49:233-239

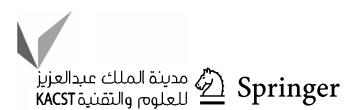


12. Wooton D (2007) The Lubricant's Nemesis-oxidation. Pract Oil Anal 9:5-6

13. Wolak A, Zając G (2018) Changes in the operating characteristics of engine oils: a comparison of the results obtained with the use of two automatic devices. Meas J Int Meas Conf 113:53-61

14. De Rivas BL, Vivancos JL, Ordieres-Meré J, Capuz-Rizo SF (2017) Determination of the total acid number (TAN) of used mineral oils in aviation engines by FTIR using regression models. Chemom Intell Lab Syst 160:32-39

15. Felkel Y, Dörr N, Glatz F, Varmuza K (2010) Determination of the total acid number (TAN) of used gas engine oils by IR and chemometrics applying a combined strategy for variable selection. Chemom Intell Lab Syst 101(1):14-22

16. Toteva V, Georgiev A, Topalova L (2009) Oxidative desulphurization of light cycle oil: monitoring by FTIR spectroscopy. Fuel Process Technol 90(7):965-970

17. Cheek GT, Mowery R (1989) Determination of antioxidants in lubricating oils using ultramicroelectrodes. Anal Chem 61(13): 1467-1469

18. Dörr N, Agocs A, Besser C, Ristić A, Frauscher M (2019) Engine oils in the field: a comprehensive chemical assessment of engine oil degradation in a passenger car. Tribol Lett 67(3):68. https:// doi.org/10.1007/s11249-019-1182-7

19. Basu A et al (2000) Smart sensing' of oil degradation and oil level measurements in gasoline engines. SAE Tech Paper Ser 1(724)

20. Zhu X, Zhong C, Zhe J (2017) Lubricating oil conditioning sensors for online machine health monitoring - a review. Tribol Int 109:473-484

21. Zhu J, He D, Bechhoefer E (2013) Survey of lubrication oil condition monitoring, diagnostics, and prognostics techniques and systems. J Chem Sci Technol 2(3):100-115
22. Soleimani M et al (2014) Base oil oxidation detection using novel chemical sensors and impedance spectroscopy measurements. Sens Actuators B Chem 199:247-258

23. Bley T, Pignanelli E, Schütze A (2014) Multi-channel IR sensor system for determination of oil degradation. J Sens Sens Syst 3(1):121-132. https://doi.org/10.5194/jsss-3-121-2014

24. Kudlaty K, Purde A, Koch AW (2004) Development of an infrared sensor for on-line analysis of lubricant deterioration. pp 903-908

25. Rauscher MS, Tremmel AJ, Schardt M, Koch AW (2017) Nondispersive infrared sensor for online condition monitoring of gearbox oil. Sensors (Switzerland) 17(2):1-12

26. Prieri F, Gresser E, Le Dreau Y, Obiols J, Kister J (2008) New method of simulation to evaluate the sensitivity to oxidation of lubricating oils: an aging cell coupled with Fourier transform infrared spectroscopy. Appl Spectrosc 62(7):810-816

27. Gołębiowski W, Wolak A, Zając G (2019) The influence on the physical and chemical properties of concentration of trace elements in used engine oils. Pet Sci Technol, pp 1-10

28. Bakar N, Abu-Siada A, Islam S, El-Naggar M (2015) A new technique to measure interfacial tension of transformer oil using uv-vis spectroscopy. IEEE Trans Dielectr Electr Insul 22(2):1275-1282

Publisher's Note Springer Nature remains neutral with regard to jurisdictional claims in published maps and institutional affiliations. 